\title{
New Frontiers in Regenerative Medicine in Cardiology: The Potential of Wharton's Jelly Mesenchymal Stem Cells
}

\author{
Simona Corrao ${ }^{\#, 1}$, Giampiero La Rocca ${ }^{\#, 1,2}$, Melania Lo Iacono ${ }^{1}$, Giovanni Zummo ${ }^{2}$, Aldo Gerbino ${ }^{3}$, \\ Felicia Farina ${ }^{2}$ and Rita Anzalone*,2
}

\author{
${ }^{I}$ Istituto Euro-Mediterraneo di Scienza e Tecnologia (IEMEST), Palermo, Italy; ${ }^{2}$ Sezione di Anatomia Umana, Diparti- \\ mento di Biomedicina Sperimentale e Neuroscienze Cliniche (BIONEC), Università degli Studi di Palermo, Italy; ${ }^{3}$ Sezi- \\ one di Istologia ed Embriologia, Dipartimento di Biomedicina Sperimentale e Neuroscienze Cliniche (BIONEC), Uni- \\ versità degli Studi di Palermo, Italy
}

\begin{abstract}
Cardiomyopathies are still the first cause of death in the world. The identification of resident stem cells, comprising those derived from sub-endocardial stroma, suggests the possible self regeneration of the heart under autocrine/paracrine modulation in the cardiac microenvironment. Nevertheless, because of the limited in vivo regeneration potential of damaged cardiac tissue, the use of drugs and ultimately cardiac transplantation remain the common treatments of heart diseases and defects. The differentiative potential of embryonic and mesenchymal stem cells (MSCs) derived from different tissues (such as bone marrow and adipose tissue) was extensively explored in cell therapy for regenerative medicine. Many groups have been focused, in recent years, on isolation, characterization, and differentiation potential of MSCs derived from perinatal (or extraembryonic) tissues, mainly the placenta and the human umbilical cord. In this review, we summarized recent works about the stemness of Wharton's jelly stromal cells and their potential in cardiac regeneration with favourable use in cell therapy and regenerative medicine. The peculiar features of these cells, as the expression of cardiac-specific transcription factors and immunomodulatory molecules suggest that human umbilical cord may be considered as a reliable alternative source of MSC useful for advanced therapy in cardiac regenerative medicine.
\end{abstract}

Keywords: Heart failure, mesenchymal stem cells, regenerative medicine, Wharton's jelly, immune modulation, tissue repair.

\section{HEART RESIDENT STEM CELLS AND THEIR LIMITATION IN CARDIAC REGENERATION}

Cardiomyopathies (congenital heart diseases, myocardium infarction, heart failure) are still the first cause of death in the world. As well reviewed by Anversa and colleagues, the concept on the heart as a post-mitotic organ featuring irreplaceable myocytes has changed during the last two decades, creating a strong debate in the scientific world [1]. In fact, the identification of human cardiac stem cells (hCSCs) which feature the essential properties of all stem cells (selfrenewal, clonogenicity, multipotency) was the basis for in vitro and in vivo studies on animal models that highlighted their ability to regenerate cardiomyocytes [2]. The regenerative ability of cardiac tissue is probably based on the activation of numerous genetic and epigentic events, as the activation of chromatin remodelling factors and transcription factors (such as GATA 4, Nkx2-5, Tbx 5) [3]. Autocrine/paracrine modulation in the cardiac microenvironment is thought to act on these resident stem cells, perhaps through the secretion of growth factors by stressed car

\footnotetext{
*Address correspondence to this author at the Dipartimento di Biomedicina Sperimentale e Neuroscienze Cliniche (BIONEC), Università degli Studi di Palermo, Via del Vespro 12990127 Palermo, Italy; Tel: 00390916553510; Fax: 00390916553580;

E-mail: rita.anzalone@unipa.it, ranzalone@hotmail.com

\#These authors contributed equally to this work.
}

diomyocytes, such as insuline-like growth factor 1 (IGF-1), hepatocyte growth factor (HGF), and stromal-derived factor 1 (SDF-1), which exert their paracrine effects on progenitor cells. In addition, these progenitor cells seem to secrete cardioprotective factors, such as adrenomedulin, connective tissue growth factor, and interleukin-1 receptor-like 1 [4]. Resident cardiac stem cells were characterized by various groups as different populations, such as $\mathrm{Lin}^{-} \mathrm{c}-\mathrm{kit}^{+}$(isolated from adult rat heart), Sca- $1^{+}$, isl $-1^{+}$cells, and side population (SP). Functional characterization experiments showed that these populations possess different efficacy in generating action potentials, expressing cardiac markers, mature sarcomeric structures formation, thus resulting in improved cardiac functionality. By contrast, these cells constitute a low percentage of total resident ones and need to be co-cultured in vitro to improve their cardiogenic potential [5-11]. The latter evidence may explain in part the poor regenerative power of the heart by itself. As well discussed by Vandervelde and co-workers, there are many signaling factors released by myocardium after injury that induce mobilization and homing of bone marrow-derived stem cells from peripheral blood to the site of cardiac damage [12]. Among these factors, hematopoietic factors (granulocyte-colony stimulating factor, G-CSF and stem cell factor, SCF), Interleukin-8 (IL-8), tumor necrosis factor-alpha (TNF- $\alpha$ ), vascular endothelial growth factor (VEGF), SDF-1 (together with its receptor CXCR4), fibroblast growth factor (FGF), IGF, HGF, 


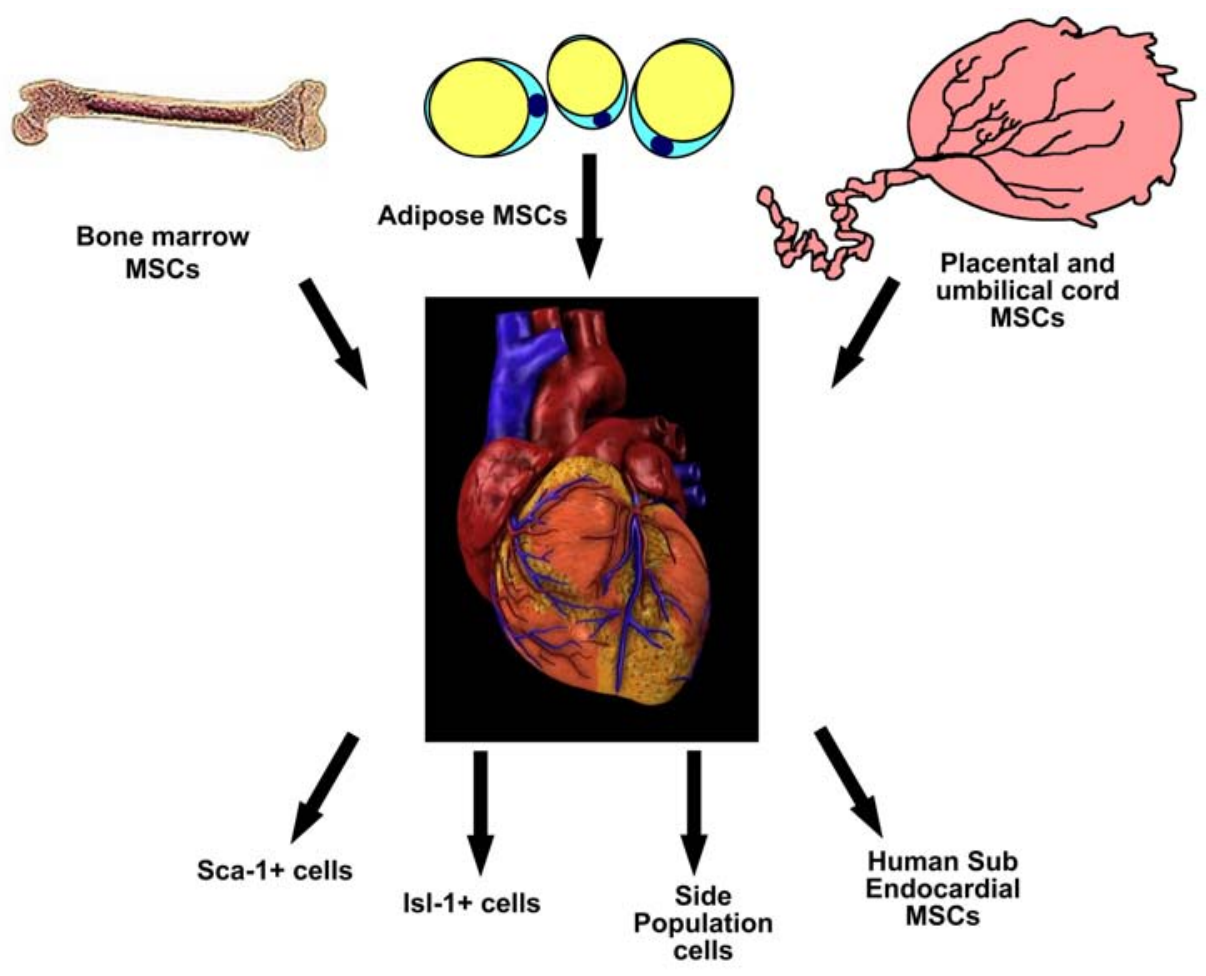

Fig. (1). Schematic representation of the main cellular sources for heart therapy compared to the main cellular populations of heart resident stem cells. Bone marrow, adipose tissue and perinatal tissues represent the main alternatives to be explored for cellular therapy of human heart. Conversely, Human hearts have been proved to contain stem/progenitor cells populations which biology has only been partly explored. No data exist on the possible interactions between endogenous and exogenous stem cells in heart repair mechanisms.

platelet-derived growth factor (PDGF), and others, seem to play pivotal roles in mobilization, homing, proliferation, differentiation, and cardiac protection [12-14]. Pathological conditions of cardiac tissue are also related to the onset of oxidative stress cascade, leading to the activation of prosurvival responses such as the expression of erythropoietin (EPO) [12], cyclooxygenase-2 and heme oxygenase-1 [15], myeloperoxidase (MPO) [16-18] and heat shock proteins (HSPs) [19-27], as well as biomarkers of nitrosative stress $[18,28]$. Because of the limited in vivo regeneration potential of damaged cardiac tissue, the use of drugs and, at last, cardiac transplantation are, at instance, the common treatments of heart diseases and defects. Nevertheless, there are many limitations to these approaches, especially related to the number of organ donors. For this reason, new frontiers in therapeutic approaches were recently focused on the application of cell therapy, strictly related with cardiac tissue engineering by design appropriate in vitro approaches and/or in vivo transplantation [29, 30]. Very recently, our group has described a new and reproducible non-enzymatic isolation method in order to obtain mesenchymal stem cells derived from sub-endocardial zone (HSE-MSCs) of human left ventricle from patients undergoing heart transplant for postinfarct chronic heart failure. We showed that these cells expressed markers and featured a differentiation potential similar to other MSC populations, as well as we reported for the first time the expression of immunomodulatory molecules, namely non-classical major histocompatibility complex (MHC) class I HLA-E and HLA-F (class Ib HLA) and costimulatory molecules B7-1 (but not B7-2) and the immunosuppressive marker B7-H3, suggesting an inhibitory effect on immune system and a favourable outcome from an immune modulation after transplantation. Moreover, these cells showed the expression of cardiac markers (connexins-26, 43 , and -45 , myosin heavy chain) and cardiac-specific transcription factors (Isl-1, Nkx 2.5, MEF2C, myocardin) [31]. The latter findings suggested and highlighted the existence of a regeneration potential in failed human hearts and deserve further investigations about new sources of MSCs with similar features to HSE-MSCs. Apart heart-derived cells, different sources of stem cells were explored to be applied in cardiac regenerative medicine, as outlined in the following sections of the review.

\section{EMBRYONIC STEM CELLS AND INDUCED PLURIPOTENT STEM CELLS}

Embryonic stem cells (ESCs), derived from inner cell mass at blastocyst stage of the embryo, are able to generate all tissue cell types, leading to the formation of the three germ layers (ectoderm, mesoderm, and endoderm), and can also differentiate into cardiomyocytes [32 and refs. therein], but they may conversely generate tumor formation and immune rejection response by the host [33, 34]. Moreover, the ethical problems related to their procurement and use, together with tumorigenity and rejection response [35], made necessary to find other sources of cells with similar behaviour. Induced pluripotent stem cells (iPSC), firstly described by Takahashi and Yamanaka in the 2006 [36] were derived 
from adult somatic cells and in vitro genetically manipulated by both viral and nonviral methods to express four factors, Oct 3/4, Sox2, Krüppel-like factor 4 (klf-4), and cellular myelocytomatosis oncogene (c-myc) (in mouse fibroblast), or together with Oct 3/4, Sox2, Nanog, and Lin28 transcription factors (in human fibroblasts) [37 and refs. therein]. Progenitor cells from other adult tissues were hypothesized as other possible source for potentially cardiogenic transdifferentation, by genetic incorporation of several transcription factors. Fibroblasts were reprogrammed towards cardiomyocytes or endothelial progenitor cells [38]. Human embryonic stem cell-derived mesenchymal stem cells, were reprogrammed to express fusogens that can create multinucleate cells [39], and selected stem cell antigen 1-negative (Sca- ${ }^{-}$) skeletal muscle [40]. A comparison between different adult somatic cells from bone marrow, hair keratinocytes, and skin fibroblasts, induced towards cardiomyocytes, showed an higher differentiation efficiency for bone marrow cells than other cell types [41]. Several differentiation methods have been reported using embryoid body formation, coculture with stromal cells (visceral endoderm-like cells), or 2D system (Matrigel) culture, and supplementation of cytokines and bone morphogenic protein (BMP) [37]. Nevertheless, some problems still remain concerning the incomplete integration of vectors and the associated risk of tumorigenesis [42]. Moreover, transplantation methods and post-transplantation efficiency of these cells need to be better improved, due to their poor survival, the reduced engraftment potential, and the safety issues. As reviewed in literature, the drug or hypoxic preconditioning of stem cells populations, in addition with growth factor cocktails, resulted in an upregulation of all those factors involved in survival, migration, myocardial tolerance, and possible differentiation towards a cardiac fate $[43,44]$.

\section{BONE MARROW AND ADIPOSE-DERIVED MES- ENCHYMAL STEM CELLS}

Adult tissues (blood, bone marrow, muscle, bone, dermis, adipose tissue, and others) host adult mesenchymal stem cells (MSCs) that can potentially differentiate into mesodermal derivatives, such as adipocytes, fibroblasts, chondrocytes, osteoblasts/osteocytes, stromal cells (reviewed in [45]) and towards neural cells (as for bone marrow-derived stem cells, BMSCs) [46], or eventually, neuron protecting cells (as for adipose-derived stem cells, ASCs) [47]. As reviewed by Elnakish and colleagues, the use of MSCs in preclinical trials (especially in experimental animal models) showed an improvement of left ventricular function, a decreased size of infarcted area, and a decreased mortality [48]. Nevertheless, bone marrow (BM) and adipose tissue (AT) were extensively studied and still remain the major sources of adult stem cells used in most clinical trials, since their transplantation seems to be related to an improvement of heart physiology [49-53]. Coculture protocols with neonatal rat ventricular myocytes highlighted the cardiogenic potential of BM-MSCs, suggesting the influence of soluble factors [54]. Studies in rat models showed the efficiency of both intravenously-injected BM-MSCs and endogenous BM-MSCs in homing and regenerating myocardium under the oral administration of cardiogenin, a natural active compound extracted from Geum japonicum, even if the use of exogenous BM-MSCs may be associated with the risks related to dangerous intramyocardial injection, as well as possible immune rejection response, and the oral administration of cardiogenin is not yet studied at pharmacodynamic and pharmacokinetic level for clinical therapy [55]. In a similar way, rat adipose-derived MSCs (ACSs) treated with phorbolmyristate acetate, a protein kinase $\mathrm{C}$ (PKC) activator, showed the expression of cardiacspecific markers (such as cardiac troponin $\mathrm{T}$, myosin light chain, myosin heavy chain) and a reduction of infarct size, interstitial fibrosis, and apoptotic index, suggesting a possible role in restoration of electromechanical function in infarcted rat hearts [56]. Zuk and co-workers analyzed the differentiation potential of adipose MSCs from human lipoaspirate towards adipogenic, osteogenic, chondrogenic, neurogenic and myogenic lineages [57]. Cardioprotection induced by BM-MSCs and ASCs seems to be related also to hypoxia condition and reduced both senescence [58] and apoptosis due to the release of VEGF and IGF-1 [59]. In parallel, the oxidative stress resulting after cardiac injury may play an important role on the prevention of apoptosis, perhaps by expression of specific receptors on BM-MSCs, such as Tolllike receptor 4 (TLR-4) (reviewed in [60]). BM-MSCs are able to differentiate in vitro towards adipocytes, chondrocytes, and osteocytes, after treatment with tissue-specific growth factor-supplied culture media [61]. As summarized by Pourrajab and co-workers, it was also supposed that the mechanisms by which BM-MSCs can reach the site of injury and exert their regulation in cardioprotection is related to the modification of extracellular matrix (ECM) under the stressed cardiac cells releasing of proteinases, such as metalloproteinases (MMPs), on the different collagen molecules [60]. MMPs constitute a broad family of extracellular proteinases which are involved in the development, function and pathogensis of several tissues and organs [62-64] as well as in immunomodulation by mesenchymal stem cells (reviewd in [65]). ECM fragments seem to be involved in BM-MSCs chemotaxis and were also associated to the subsequent downregulation of collagen synthesis by resident cardiac fibroblasts [60]. Remodelling of ECM and its alterations exerted by MMPs under stress conditions may critically affect microenvironmental influence on adult cardiac progenitor cells and cardiac regeneration potential [66]. These findings highlighted that paracrine molecules may have crucial therapeutic effects in cardioprotection and regeneration. Despite their extensive use in research, adipose tissue and bone marrow are still affected by heterogeneity of the cell phenotype [51, 67], highlighting the complexity to isolate specific subpopulation, such as mesenchymal stem cells (MSCs). Moreover, the amount of MSCs that can be isolated from bone marrow is too low (estimated at about 0.001 to $0,01 \%$ for $1.073 \mathrm{~g} / \mathrm{ml}$ of bone marrow aspirate) [61], because also the problem related to the availability of bone marrow tissue. In contrast to other adult stem cells, BM-MSCs were phenotypically described as non-hematopoietic (CD14, CD34-, and $\mathrm{CD}^{\circ} 5^{-}$) fibroblast-like cells, that are negative also for endothelial marker CD31, and possess a specific immunomodulatory activity, due to the absence of MHC class II and co-stimulatory molecules (CD80- $\left.{ }^{-} \mathrm{CD} 86^{-}\right)$that may render $\mathrm{T}$ lymphocytes anergic (reviewed in [68]), suggesting the possibility of allogeneic transplantation. 


\section{HUMAN UMBILICAL CORD: THE HIDDEN PO- TENTIAL OF A DISCARDED TISSUE}

Despite the extensive use of BM-MSCs in pre-clinical studies, many groups were involved, in recent years, on isolation, characterization, and differentiation potential of MSCs derived foetus-associated organs, known as perinatal (or extraembryonic) tissues, mainly the placenta and the human umbilical cord. Currently, they are both discarded as a waste of the labour, but they proved to contain large numbers of multipotent mesenchymal cells, which were supposed to feature intermediate characteristics between embryonic and adult stem cells [69]. The amnios has shown to bear adherent MSCs with classical pattern of molecular markers and multipotency (as shown by in vitro differentiation towards endodermal, mesodermal, and ectodermal lineages) [70]. These cells express cardiac-specific transcription factors (such as those belonging to GATA family), and MHC class I molecules HLA-A, -B, and -C. It has been demonstrated that these cells exert in vivo a differentiative potential towards cardiomyocytes and result in improved cardiac function [71, 72]. Moreover, as well demonstrated by Park et al. (2011), perivascular cells from placental villi showed adhering and migratory behaviour and myogenic differentiation in both in vitro and in vivo experiments [73]. Parolini's group well reviewed and analyzed regenerative potential of placentaderived cells [74]. Moreover, they demonstrated the effect of human amniotic membrane fragments on restoration of cardiac ischemia (in a rat model), showing an amelioration of cardiac dysfunction $[75,76]$. These effects may be due to release of mediators rather than direct differentiation of amniotic cells. Placenta-derived amniotic MSCs were also analyzed and proposed for use in therapy, due to their immunomodulatory activity (exerted by the inhibition of $\mathrm{T}$ lymphocyte proliferation) for which the release of prostaglandins has been suggested at the main mechanism [77]. Recent data highlighted the human umbilical cord (hUC) as a source of mesenchymal stromal cells. hUC is an extraembryonic formation that originates at day 13 of the embryonic development [78] that connects foetus and mother during pregnancy through the placenta. At term, HUC consists of a simple squamous epithelium (except the cubical amniotic epithelium at the junction of the cord with the placenta), which embrace three major vessels (two arteries and one vein) immersed in a surrounding connective tissue (mature mucous connective tissue), which does not present neither lower calibre vascular structures nor neural elements [79]. The stromal connective tissue consists of an abundant ECM distinguishable in three zones, the subamniotic stroma, the Wharton's jelly (WJ), and the vessels' adventitia, and rich in collagen (types I, III and VI) and in basement membrane molecules such as collagen type IV, laminin and heparan sulphate proteoglycan $[80,81]$. Type VII collagen is expressed in the epithelium and in the endothelial cells, but it was found as predominately expressed by fibroblast-like stromal cells [82]. ECM components are a storage of growth factors (including IGFs, FGFs and TGF- $\beta$ ) that sustain these stromal cells [83] (Sobolewski et al., 2005). The abundant ECM of umbilical cord stroma contain dispersed stromal mesechymal stem cells (MSCs). Studies by Takechi and colleagues [84] referred to these cells as 'myofibroblasts', a term firstly used by Majno and colleagues (1971) [85, 86].
Wharton's jelly cells (WJCs) are fibroblast-like cells sharing common markers (such as CD13, CD29, CD44, CD73, CD90, CD105, $\alpha$-smooth muscle actin, and vimentin) with other MSCs [87-91]. Since many protease-based isolation protocols described in literature could lead to damages to surface molecules, we set up and standardized an in vitro non-enzymatic isolation protocol of stromal cells from WJ, named Wharton's jelly cells (WJCs) or 'human extraembryonic mesoderm stem cells' (HEMSCs), on the basis of the migratory capability of mesenchymal cells to the plastic surface of culture flasks, thus preventing cell membrane proteins integrity [92]. These cells showed a fibroblastoid morphology, genetic stability, telomere activity, and good cloning efficiency (10-12\%) after several passages in culture, a pattern of markers similar to other mesenchymal stem cells (including CD10 and CD13), at both protein and RNA level. They featured multipotency and were differentiated into osteoblasts and adipocytes. We also suggested a possible immune suppression mechanism due to the expression of molecules involved in $\mathrm{T}$ cell response inhibition, such as a particular MHC class I, HLA-G, normally expressed by trophoblastic lineage in order to inhibit NK cells response versus allogeneic foetus [92]. As reviewed by Prasanna and Jahanavi (2011), WJCs showed a lymphoproliferative suppression stronger than those exerted by BM-MSCs [93]. Moreover, we demonstrated that WJCs maintained immunomodulatory molecules (HLA-G, -E, and -F) also after differentiation in vitro, supporting our concept about the large plasticity of these cells and their use in regenerative medicine for allogeneic therapy [92, 94-98]. As for placentaderived MSCs described above, also in WJCs lymphoproliferative inhibition was linked to the expression and release of soluble factors as prostaglandins [99] and IL-10 [100]. Immune tolerance instauration during pregnancy (thus preventing rejection of allogeneic foetus) is also ensured by the release of soluble $10 \mathrm{kDa}$ Heat Shock Protein (HSP10), also known in literature as Early Pregnancy Factor (EPF) by placental structures [101]. In addition, we demonstrated that these cells do express CD68, a typical monocyte/macrophage cells marker at both protein and mRNA level [102]. This result highlighted the need to understand and to explain the biological function of 'non-classical' patterns, taking into account the novel panel of markers which we previously described, such as the expression of costimulatory CD80 (B7-1), but not of CD86 (B7-2), and the expression of HLAA and especially HLA-G, but not of HLA-DR (MHC class II) [92]. Moreover, Zhou and colleagues described a reduced secretion of TGF- $\beta$ and IFN- $\gamma$ by lymphocytes induced in co-culture with WJCs [103]. Thus their immunomodulatory capability support our hypothesis about their possible use in regenerative medicine. Moreover, the expression of vimentin, $\alpha$-smooth muscle actin, and cardiac-specific molecules, mainly connexin 43, c-kit/CD117, GATA 4 [92, 104], reinforces the concept that hUC is a novel and promising source of readily available autologous cells for cardiac tissue engineering. This concept would be applied not only to improve damages related to heart failure or ischemia, but also to provide innovative therapies for paediatric patients with congenital heart pathologies and defects [105-107]. Costa Pereira and colleagues isolated WJCs with an enzymatic protocol. The cells underwent differentiation towards car- 
diomyocytes, using 5-azacytidine. After 21 days the adherent cells showed cardiomyogenic morphology and a slight spontaneous beating [108]. Hollweck et al. (2011) described the effect of six different cardiac differentiation protocols on WJCs, assessing the efficiency of oxytocin with respect to 5azacytidine [109]. Nevertheless, the use of enzyme isolation protocols may drastically induce damages on surface markers that could result in modification in phenotype characterization and regarding their response when transplanted in vivo. Future investigation is needed in order to unify isolation protocols, create co-banking of WJCs, and establishing hUC as a reliable source of stem cells without ethical and safety issues [110]. Moreover, little is known about differentiation of WJCs towards cardiomyocytes with both in vitro and in vivo experiments for further application in pre-clinical and clinical trials.

\section{CONFLICT OF INTEREST}

Dr. La Rocca is member of the Scientific Board of Auxocell Laboratories, Inc. The funders had no role in article design, data collection, decision to publish, or preparation of the manuscript.

\section{ACKNOWLEDGEMENTS}

Authors' results referred to in this paper were in part supported by University of Palermo grants (ex 60\% 2007) to RA, FF, GLR and Istituto Euro-Mediterraneo di Scienza e Tecnologia (IEMEST) to GLR.

\section{REFERENCES}

[1] Anversa P, Leri A, Kajstura J. Cardiac regeneration. J Am Coll Cardiol 2006; 47 (9): 1769-76.

[2] Bearzi C, Rota M, Hosoda T, et al. Human cardiac stem cells. Proc Natl Acad Sci 2007; 104 (35): 14068-73.

[3] van Weerd JH, Koshiba-Takeuchi K, Kwon C, Takeuchi JK. Epigenetic factors and cardiac development. Cardiovasc Res 2011; 91 (2): 203-11.

[4] Mirotsou M, Jayawardena TM, Schmeckpeper J, Gnecchi M, Dzau VJ. Paracrine mechanisms of stem cell separative and regenerative actions in the heart. J Mol Cell Cardiol 2011; 50 (2): 280-9.

[5] Beltrami AP, Urbanek K, Kajstura J, et al. Evidence that human cardiac myocytes divide after myocardial infarction. N Engl J Med 2001; 344 (23): 1750-7.

[6] Beltrami AP, Barlucchi L, Torella D, et al. Adult cardiac stem cells are multipotent and support myocardial regeneration. Cell 2003; 114 (6): 763-76

[7] Leontiadis E, Manginas A, Cokkinos DV. Cardiac repair - fact or fancy? Heart Fail Rev 2006; 11 (2): 155-70.

[8] Barile L, Messina E, Giacomello A, Marbàn E. Endogenous cardiac stem cells. Prog Cardiovasc Dis 2007; 50 (1): 31-48.

[9] Guan K, Hasenfuss G. Do stem cells in the heart truly differentiate into cardiomyocytes? J Mol Cell Cardiol 2007; 43 (4): 377-87.

[10] Schuldt AJT, Rosen MR, Gaudette GR, Cohen IS. Repairing damaged myocardium: evaluating cells used for cardiac regeneration. Curr Treat Opt Cardiovasc Med 2008; 10(1): 59-72.

[11] Khattar P, Friedrich FW, Bonne G, et al. Distinction between two population of islet-1-positive cells in hearts of different murine strains. Stem Cells Dev 2011; 20 (6): 1043-52.

[12] Vandervelde S, van Luyn MJA, Tio RA, Harmsen MC. Signaling factors in stem cell- mediated repair of infarcted myocardium. J Mol Cell Cardiol 2005; 39 (2): 363-76.

[13] Hwang $\mathrm{H}$, Kloner RA. Improving regenerating potential of the heart after myocardial infarction: factor-based approach. Life Sci 2010; 86 (13-14): 461-72.

[14] Wiehe JM, Kaya Z, Homann JM, et al. GMP-adapted overexpression of CXCR4 in human mesenchymal stem cells for cardiac reapir. Int J Cardiol 2012; [Epub ahead of print].
[15] Takeda K, Lin j, Okubo S, et al. Transient glugose deprivation causes upregulation of heme oxygenase- 1 and cyclooxygenase- 2 expression in cardiac fibroblasts. J Mol Cell Cardiol 2004; 36 (6): 821-30.

[16] La Rocca G, Di Stefano A, Eleuteri E, et al. Oxidative stress induces myeloperoxidase expression in endocardial endothelial cells from patients with chronic heart failure. Basic Res Cardiol 2009; 104 (3): 307-20.

[17] Anzalone R, La Rocca G, Di Stefano A, et al. Role of endothelial cell stress in the pathogenesis of chronic heart failure. Front Biosci 2009; 14: 2238-47.

[18] Eleuteri E, Di Stefano A, Ricciardolo FL, et al. Increased nitrotyrosine plasma levels in relation to systemic markers of inflammation and myeloperoxidase in chronic heart failure. Int $\mathrm{J}$ Cardiol 2009; 135 (3): 386-90.

[19] Lau S, Patnaik N, Sayen MR, Mestril R. Simultaneous overexpression of two stress proteins in rat cardiomyocytes and myogenic cells confers protection against ischemia-induced injury. Circulation 1997; 96 (7): 2287-94.

[20] Lin KM, Lin B, Lian IY, Mestril R, Scheffler IE and Dillmann WH. Combined and individual mitochondrial HSP60 and HSP10 expression in cardiac myocytes protects mitochondrial function and prevents apoptotic cell deaths induced by simulated ischemiareoxygenation. Circulation 2001; 103 (13): 1787-92.

[21] Gupta S, Knowlton AA. Cytosolic heat shock protein 60, hypoxia, and apoptosis. Circulation 2002; 106 (21): 2727-33.

[22] Kirchhoff SR, Gupta S, Knowlton AA. Cytosolic heat shock protein 60, apoptosis, and myocardial injury. Circulation 2002; 105 (24): 2899-904.

[23] Shan YX, Liu TJ, Su HF, Samsamshariat A, Mestril R, Wang PH. Hsp10 and Hsp60 modulate Bcl-2 family and mitochondria apoptosis signaling induced by doxorubicin in cardiac muscle cells. J Mol Cell Cardiol 2003; 35 (9): 1135-43.

[24] Maurel A, Azarnoush K, Sabbah L et al. Can cold or heat shock improve skeletal myoblast engraftment in infracted myocardium? Transplantation 2005; 80 (5): 660-5.

[25] Gupta S, Knowlton AA. HSP60 trafficking in adult cardiac myocytes: role of the exosomal pathway. Am J Physiol Heart Circ Physiol 2007; 292 (6): H3052-6.

[26] Wang X, Zhao T, Huang W, et al. Hsp20-engineered mesenchymal stem cells are resistant to oxidative stress via enhanced activation of Akt and increased secretion of growth factors. Stem Cells Dec 2009; 27 (12): 3021-31.

[27] Wang Y, Chen L, Hagiwara N, Knowlton AA. Regulation of heat shock protein 60 and 72 expression in failing heart. J Mol Cell Cardiol 2010; 48 (2): 360-6.

[28] Eleuteri E, Magno F, Gnemmi I, et al. Role of oxidative and nitrosative stress biomarkers in chronic heart failure. Front Biosci 2009; 14: 2230-7.

[29] Stubbs SL, Crook JM, Morrison WA, Newcomb AE. Toward clinical application of stem cells for cardiac regeneration. Heart Lung Circ 2011; 20 (3): 173-9.

[30] Vunjak-Novakovic G, Lui KO, Tandon N, Chien KR. Bioengineering heart muscle: a paradigm for regenerative medicine. Annu Rev Biomed Eng 2011; 13: 245-67.

[31] Anzalone R, Corrao S, Lo Iacono M, et al. Isolation and characterization of CD276+/HLA-E+ human sub-endocardial mesenchymal stem cells from chronic heart failure patients: analysis of differentiative potential and immunomodulatory markers expression. Stem Cell Dev 2013; 22(1): 1-17.

[32] Martin CM. Review of stem cell-based therapy for the treatment of cardiovascular disease. J Cardiovasc Trans Res 2008; 1 (2): 10614.

[33] Yang S, Lin G, Deng L, Lu G-X. Tumourigenic characteristics of embryonal carcinoma cells as a model studying tumour progression of human embryonic stem cells. Cell Prolif 2012; 45 (4): 299-310.

[34] Swijnenburg R-J, Tanaka M, Vogel H, et al. Embryonic stem cell immunogenicity increases upon differentiation after transplantation into ischemic myocardium. Circulation 2005; 112 (9 Suppl): I16672.

[35] Abdelwahid E, Siminiak T, Guarita-Souza LC, et al. Stem cell therapy in heart diseases: a review of selected new perspectives, pratical consideration and clinical applications. Curr Cardiol Res 2011; 7 (3): 201-12. 
[36] Takahashi K, Yamanaka S. Induction of pluripotent stem cell from mouse embryonic and adult fibroblast cultures by defined factors. Cell 2006; 126 (4): 663-76.

[37] Yoshida Y, Yamanaka S. iPS cells: a source of cardiac regeneration. J Mol Cell Cardiol 2011; 50 (2): 327-32.

[38] Xie X, Sun A, Huang Z, et al. Another possible source for cardiac regenerative medicine: reprogramming adult fibroblasts to cardiomyocytes and endothelial progenitor cells. Med Hypotheses 2011; 76 (3): $365-7$

[39] Kouris NA, Schaefer JA, Hatta M, et al. Direct fusion of mesenchymal stem cells with cardiomyocytes via VSV-G facilitates stem cell programming. Stem Cell Int 2012; 2012: 414038..

[40] Zuba-Surma EK, Abdel-Latif A, Case J, et al. Sca-1 expression is associated with decreased cardiomyogenic differentiation potential of skeletal muscle-derived adult primitive cells. J Mol Cell Cardiol 2006; 41 (4): 650-60.

[41] Streckfuss-Bömeke K, Wolf F, Azizian A, et al. Comparative study of human-induced pluripotent stem cells derived from bone marrow cells, hair keratinocytes, and skin fibroblasts. Eur Heart J 2012; [Epub ahead of print].

[42] Egashira T, Yuasa S, Fukuda K. Induced pluripotent stem cells in cardiovascular medicine. Stem Cell Int 2011;2011: 348960.

[43] Mayorga M, Finan A, Penn M. Pre-implantation specification of stem cell to cardiac lineage for regeneration of cardiac tissue. Stem Cell Rev Rep 2009; 5 (1): 51-60.

[44] Schoenhard JA, Hatzopoulos AK. Stem cell therapy: pieces of the puzzle. J Cardiovasc Trans Res 2010; 3 (1): 49-60.

[45] Tuan RS, Boland G, Tuli R. Adult mesenchymal stem cells and cell-based tissue engineering. Arthritis Res Ther 2003; 5 (1): 32-45.

[46] Arnhold S, Klein H, Klinz F-J, Absenger Y, et al. Human bone marrow stroma cells display certain neural characteristics and integrate in the subventricular compartment after injection into the liquor system. Eur J Cell Biol 2006; 85 (6): 551-65.

[47] Kim J-M, Lee S-T, Chua K, et al. Systemic transplantation of human adipose stem cells attenuated cerebral inflammation and degeneration in a hemorrhagic stroke model. Brain Res 2007; 1183: 43-50.

[48] Elnakish MT, Hassan F, Dakhlallah D, Marsh CB, Alhaider IA, Khan M. Mesenchymal stem cells for cardiac regeneration: translation to bedside reality. Stem Cell Int 2012; 2012: 646038

[49] Chen S-L, Fang W-W, Ye F, et al. Effect on left ventricular function of intracoronary transplantation of autologous bone marrow mesenchymal stem cells in patients with acute myocardial infarction. Am J Cardiol 2004; 94 (1): 92-5.

[50] Abdel-Latif A, Bolli R, Tleyjeh IM, et al. Adult bone marrowderived cells for cardiac repair: a systematic review and metaanalysis. Arch Intern Med 2007; 167 (10): 989-97.

[51] Bai X, Alt E. Myocardial regeneration potential of adipose tissuederived stem cells. Biochem Biophys Res Comm 2010; 401 (3): $321-6$

[52] Choundry FA, Mathur A. Stem cell therapy in cardiology. Regen Med 2011; 6 (6 suppl): 17-23

[53] Choi SH, Jung SY, Kwon S-M, Baek SH. Perspective on stem cell therapy for cardiac regeberation-advences and challenges. Circ J 2012; 76 (6): 1307-12

[54] Li XH, Lin QX, Deng CY, Shan ZX, Yang M, Lin SG. Bone marrow mesenchymal stem cells differentiate into functional cardiac phenotypes by cardiac microenvironment. J Mol Cell Cardiol 2007; 42 (2): 295-303

[55] Lin X, Peng P, Cheng L, et al. A natural compound induced cardiogenic differentiation of endogenous MSCs for repair of infracted heart. Differentiation 2012; 83 (1): 1-9.

[56] Chang W, Lim S, Song B-W, et al. Phorbol myristate acetate differentiates human adipose-derived mesenchymal stem cells into functional cardiogenic cells. Biochem Biophysic Res Comm 2012; 424(4): 740-6.

[57] Zuk PA, Zhu M, Ashjian P, et al. Human adipose tissue is a source of multipotent stem cells. Mol Biol Cell 2002; 13 (12): 4279-95.

[58] Cai B, Zhu S, Li J, Chen N, Liu Y, Lu Y. Bone marrow-derived mesenchymal stem cells protected rat cardiomyocytes from premature senescense. Int J Cardiol 2012; 154 (2): 180-2.

[59] Sadat S, Gehmert S, Song Y-H, et al. The cardioprotective effect of mesenchymal stem cells is mediated by IGF-I and VEGF. Biochem Biophysic Res Comm 2007; 363 (3): 674-9.
[60] Pourrajab F, Forouzannia SK, Tabatabaee SA. Molecular characteristics of bone marrow mesenchymal stem cells: an appealing source for regenerative medicine. Heart Lung Circ 2012; [Epub ahead of print].

[61] Pittenger MF, Mackay AM, Beck SC, et al. Multilineage Potential of Adult Human Mesenchymal Stem Cells Science 1999; 284 (5411): 143-7.

[62] Pucci-Minafra I, Minafra S, La Rocca G, et al. Zymographic analysis of circulating and tissue forms of colon carcinoma gelatinase A (MMP-2) and B (MMP-9) separated by mono- and twodimensional electrophoresis. Matrix Biol 2001; 20: 419-27.

[63] La Rocca G, Pucci-Minafra I, Marrazzo A, Taormina P, Minafra S. Zymographic detection and clinical correlations of MMP-2 and MMP-9 in breast cancer sera. Br J Cancer 2004; 90 (7): 1414-21.

[64] La Rocca G, Anzalone R, Magno F, Farina F, Cappello F, Zummo G. Cigarette smoke exposure inhibits extracellular MMP-2 (gelatinase A) activity in human lung fibroblasts. Resp Res 2007; 8: 23.

[65] La Rocca G, Corrao S, Lo Iacono M, Corsello T, Farina F, Anzalone R. Novel immunomodulatory markers expressed by WJMSC: an updated review in regenerative and reparative medicine. Open Tissue Eng Regen Med J 2012; 5: 50-8.

[66] Bayomy AF, Bauer M, Qju Y, Liao R. Regeneration in heart disease - is ECM the key?. Life Sci 2012; 91 (17-18): 823-7.

[67] Liao R, Pfister O, Jain M, Mouquet F. The bone marrow-cardiac axis of myocardial differentiation. The bone marrow-cardiac axis of myocardial regeneration. Progr Cardiovasc Dis 2007; 50 (1): 1830

[68] Chamberlain G, Fox J, Ashton B, Middleton J. Concise review: mesenchymal stem cells: their phenotype, differentiation capacity, immunological features and potential for homing. Stem Cell 2007; 25 (11): 2739-49.

[69] Pappa KI, Anagnou NP. Novel sources of fetal stem cells: where do they fit on the developmental continuum? Regen Med 2009; 4 (3): 423-33.

[70] Díaz-Prado S, Muiños-López E, Hermida-Gómez T, et al. Human amniotic membrane as an alternative source of stem cells for regenerative medicine. Differentiation 2011; 81 (3): 162-71.

[71] Walther G, Gekas J, Bertrand OF. Amniotic stem cells for cellular cardiomyoplasty. Catheter Cardiovasc Interv 2009; 73 (7): 917-24.

[72] Fang C-H, Jin J, Joe J-H, et al. In vivo differentiation of human epithelial cells into cardiomyocyte-like cells and cell transplantation effect on myocardial infarction in rats: comparison with cord blood and adipose tissue-derived mesenchymal stem cells. Cell Transplant 2012; 21(8): 1687-96..

[73] Park TS, Gavina M, Chen C-W, et al. Placental perivascular cells for human muscle regeneration. Stem Cell Dev 2011; 20 (3): 451 63.

[74] Evangelista M, Soncini M, Parolini O. Placenta-derived stem cells: new hope for cell therapy? Cytotechnology 2008; 58 (1): 33-42.

[75] Cargnoni A, Di Marcello M, Campagnol M, Nassuato C, Albertini A, Parolini O. Amniotic membrane patching promotes ischemic rat heart repair. Cell Transplant 2009; 18 (10): 1147-59.

[76] Parolini O, Caruso M. Review: preclinical studies on placentaderived cells and amniotic membrane: an update. Placenta 2011; 25 (Suppl 2): S186-95.

[77] Rossi D, Pianta S, Magatti M, Sedlmayr P, Parolini O. Characterization of th conditionated medium from amniotic membrane cells. Prostaglandins as a key effectors of its immunomodulatory activity. PLoS One 2012; 7 (10): e46956.

[78] Karahuseyinoglu S, Cinar O, Kilic E, et al. Biology of stem cells in human umbilical cord stroma: in situ and in vitro surveys. Stem Cell 2007; 25 (2): 319-31.

[79] Hoyes AD. Ultrastructure of the epithelium of the human umbilical cord. J Anat 1969; 105 (Pt1): 149-62.

[80] Nanaev AK, Kohen G, Milovanov AP, Domogatsky SP, Kaufmann P. Stromal differentiation and architecture of the human umbilical cord. Placenta 1997; 18 (1): 53-64

[81] Can A, Karahuseyinoglu S. Concise review: human umbilical cord stroma with regard to the source of fetus-derived stem cells. Stem Cells 2007; 25 (11): 2886-95.

[82] Ryynänen J, Tan EM, Hoffren J, Woodley DT, Sollberg S. Type VII collagen gene expression in human umbilical tissue and cells. Lab Invest 1993; 69 (3): 300-4. 
[83] Sobolewski K, Małkowski A, Bańkowski E, Jaworski S. Wharton's jelly as a reservoir of peptide growth factors. Placenta 2005; 26 (10): 747-52.

[84] Takechi K, Kuwabara Y, Mizuno M. Ultrastructural and immunohistochemical studies of Wharton's jelly umbilical cord cells. Placenta 1993; 14 (2): 235-45.

[85] Majno G, Gabbiani G, Hirschel BJ, Ryan GB, Statkov PR. Contraction of granulation tissue in vitro: similarity to smooth muscle. Science (Washington) 1971; 173 (3996): 548-50.

[86] Gabbiani G, Hirschel BJ, Ryan GB, Statkov PR, Majno G. Granulation tissue as a contractile organ. J Exp Med 1972; 135 (4): 71934.

[87] Kobayashi K, Kubota T, Aso T. Study on myofibroblast differentiation in the stromal cells of Wharton's jelly: expression and localization of alpha-smooth muscle actin. Early hum Dev 1998; 51 (3): 223-33.

[88] Qiao C, Xu W, Zhu W, et al. Human mesenchymal stem cells isolated from the umbilical cord. Cell Biol Int 2008; 32 (1): 8-15.

[89] Conconi MT, Di Liddo R, Tommasini M, Calore C, Parnigotto PP. Phenotype and differentiation potential of stromal populations obtained from various zones of human umbilical cord: an overview. Open Tissue Eng Regen Med J 2011; 4 (1): 6-20.

[90] Jeschke MG, Gauglitz GG, Phan TT, Herndon DN, Kita K. Umbilical cord lining membrane and Wharton's jelly-derived mesenchymal stem cells: the similarities and differences. Open Tissue Eng Regen Med J 2011; 4 (1): 21-7.

[91] De Kock J, Najar M, Bolleyn J, et al. Mesoderm-derived stem cells: the link between the transcriptome and their differentiation potential. Stem Cells Dev 2012; 21(18): 3309-33.

[92] La Rocca G, Anzalone R, Corrao S, et al. Isolation and characterization of Oct-4+/HLA-G+ mesenchymal stem cells from human umbilical cord matrix: differentiation potential and detection of new markers. Histochem Cell Biol 2009; 131 (2): 267-82.

[93] Prasanna SJ, Jahnavi VS. Wharton's jelly mesenchymal stem cells as off-the-shelf cellular therapeutics: a closer look into their regenerative and immunomodulatory properties. Open Tissue Eng Regen Med J 2011; 4 (1): 28-38

[94] Anzalone R, Lo Iacono M, Corrao S, et al. New emerging potentials for human Wharton's jelly mesenchymal stem cells: immunological features and hepatocyte-like differentiative capacity. Stem Cell Dev 2010; 19 (4): 423-38.

[95] Anzalone R, Lo Iacono M, Loria $\mathrm{T}$, et al. Wharton's jelly mesenchymal stem cells as candidates for beta cells regeneration: extending the differentiative and immunomodulatory benefits of adult mesenchymal stem cells for the treatment of type 1 diabetes. Stem Cell Rev 2011; 7 (2): 342-63.

[96] Anzalone R, Farina F, Zummo G, La Rocca G. Recent patents and advances on isolation and cellular therapy applications of mesenchymal stem cells from human umbilical cord Wharton's jelly. Recent Pat Regen Med 2011; 1: 216-27.

[97] Lo Iacono M, Anzalone R, Corrao S, et al. Perinatal and Wharton's jelly-derived mesenchymal stem cells in cartilage regenerative medicine and tissue engineering strategies. Open Tissue Eng Regen Med J 2011; 4 (1): 72-81.

[98] Anzalone R, Lo Iacono M, Corrao S, et al. Human Wharton's jellyderived mesenchymal stem cells express several immunomodulatory molecules both in their naïve state and hapatocyte-like differentiated progeny: prospects for their use in liver diseases. Placenta 2011; 32 (Suppl 4): S335.

[99] Najar M, Raicevic G, Boufker HI, et al. Mesenchymal stromal cells use PGE2 to modulate activation and proliferation of lymphocyte subsets: combined comparison of adipose tissue, Wharton's jelly and bone marrow source. Cell Immunol 2010; 264 (2): 171-9.

[100] Dayan V, Yannarelli G, Billia F, et al. Mesenchymal stromal cells mediate a switch to alternatively activated monocytes/macrophages after acute myocardial infarction. Basic Res Cardiol 2011; 106 (6) 1299-310.

[101] Corrao S, Campanella C, Anzalone R, et al. Human Hsp10 and Early Pregnancy Factor (EPF) and their relationship and involvement in cancer and immunity: current knowledge and perspectives. Life Sci 2010; 86 (5-6): 145-52.

[102] La Rocca G, Anzalone R, Farina F. The expression of CD68 in human umbilical cord mesenchymal stem cells: new evidences of presence in non-myeloid cell types. Scand J Immunol 2009; 70 (2): 161-2.

[103] Zhou C, Yang B, Tian Y, et al. Immunomodulatory effect of human umbilical cord Wharton's jelly-derived mesenchymal stem cells on lymphocytes. Cell Immunol 2011; 272 (1): 33-8.

[104] Kadner A, Zund G, Maurus C, et al. Human umbilical cord cells for cardiovascular tissue engineering: a comparative study. Eur J Cardiothorac Surg 2004; 25 (4): 635-41.

[105] Turillazzi E, La Rocca G, Anzalone R, et al. Heterozygous nonsense SCN5A mutation W822X explains a simultaneous sudden infant death syndrome. Virchows Arch 2008; 453 (2): 209-16.

[106] Turillazzi E, Pomara C, La Rocca G, et al. Immunohistochemical marker for $\mathrm{Na}+\mathrm{CP}$ type Valpha $(\mathrm{C}-20)$ and heterozygous nonsense SCN5A mutation W822X in a sudden cardiac death induced by mild anaphylactic reaction. Appl Immunohistochem Mol Morphol 2009; 17 (4): 357-62.

[107] Breymann C, Schmidt D, Hoerstrup SP. Umbilical cord cells as a source of cardiovascular tissue engineering. Stem Cell Rev 2006; 2 (2): 87-92

[108] Costa Pereira W, Khushnooma I, Madkaikar M, Ghosh K. Reproducible methodology for the isolation of mesenchymal stem cells from human umbilical cord and its potential for cardiomyocyte generation. J Tissue Eng Reg Med 2008; 2: 394-9.

[109] Hollweck T, Hartmann I, Eblenkamp M, et al. Cardiac Differentiation of Human Wharton`s jelly stem cells-Experimental comparison of protocols. Open Tissue Eng Regen Med J 2011; 4: 95-102.

[110] La Rocca G. Connecting the dots: the promises of Wharton's jelly mesenchymal stem cells for tissue repair and regeneration. Open Tissue Eng Regen Med J 2011; 4: 3-5. 